\title{
PROPOSTA ALTERNATIVA PARA A PRODUÇÃO CIENTIFICA DE ENFERMEIROS ASSISTENCIAIS
}

\author{
Magali Roseira Boemer* \\ Branca Maria de Oliveira Santos** \\ Olga Maimoni Aguillar ** \\ Maria José Rossato Stopa***
}

BOEMER, M.R.; SANTOS, B.M. de O.; AGUILLAR, O.M.; STOPA, M.J.R. Proposta alternativa para a produção científica de enfermeiros assistenciais. Rev. Esc. Enf. USP, São Paulo, 24(2):211-223, ago. 1990.

$O$ trabalho pretende relatar a experiência de cursos de extensão universitária sobre metodologias de pesquisa, destinados a enfermeiros assistenciais de pesquisa, destinados a enfermeiros assistenciais com a finalidade de fornecer-lhes alguma fundamentação a respeito do tema. Esses cursos ministrados em 1984, 1986 e 1988 pela Escola de Enfermagem de Ribeirão Preto-USP foram propostos frente da postura de sua coordenação de que é precisa estimular a produção cientifica dos enfermeiros assistenciais; assim, os cursos tinham como proposta básica promover este estímulo. Para tanto procurou-se, ao lado de conteúdo sobre as diversas metodologias, associar discussão de trabalhos de pesquisa em enfermagem que se mostrassem relevantes para a prática. Decorrido algum tempo da realização desses cursos, pretendeu-se resgatar dos enfermeiros egressos dos mesmos, algumas informaçōes que pudessem nortear o direcionamento de cursos futuros assim como avaliar a contribuiçấo que os mesmos tenham dado no sentido de estimular a produção cientifica dos enfermeiros assistenciais.

UNITERMOS: Pesquisa em enfermagem. Prática da enfermagem. Educação em enfermagem.

\section{INTRODUÇĀO}

Ao terminarem o curso de graduação, os profissionais de enfermagem demonstram uma avidez por desempenharem a prática como forma de complementar os conhecimentos que durante o curso não tenham encontrado espaço para consolidação. Entretanto, quando se sentem seguros, "dominando a prática" na sua área de atuação, essa mesma prá. tica se esvazia e passa a não lhes trazer satisfações em termos de realização pessoal.

Nesse momento, pode iniciar-se um processo de reflexão e análise do seu trabalho enquanto profissional da saúde, que culmina com a identificação da necessidade de manter-se atualizado de forma mais científica, através de uma sistematização de seus conhecimentos.

\footnotetext{
- Professor Associado da Escola da Enfermagem de Ribeiráo Preto - USP.

* Professor Doutor da Bscola de Itnfermagem de Ribelrăo Preto - USP.

*** Diretora de Servico do Hospital das Clínicas de Ribeiräo Preto - BP.
} 
Em linhas gerais, pode-se dizer que inicia-se uma fase de indagaçōes e busca de novos conhecimentos, baseados em princípios lógicos, com 0 objetivo de adicionar aigo ou contribuir para o conhecimento científico, para a tomada de decisões e resolução de problemas relacionados á prática.

Nesse sentido, em estudo realizado por LOPES ${ }^{6}$ sobre a produção dos enfermeiros assistenciais em relação à pesquisa, foi possível verificar que eles foram unânimes em corsiderar a pesquisa como um instrumento de suma importância para a profissão, que ela contribui para melhorar a prática e o serviço, que proporciona novos conhecimentos e que, aliada ao serviço de enfermagem, excelente campo para o seu desenvolvimento, constitui-se numa forma de acesso à afirmação da profissão no futuro.

No entanto é preciso considerar que a pesquisa em enfermagem se ciesenvolveu como tal há aproximadamente um quarto de século, iniciando-se e restringindo-se praticamente aos cursos de pós-graduação oriundos da Reforma Universitária ${ }^{1}$ e que é relativamente pequeno o envolvimento de enfermeiros assistenciais em pesquisa, sendo que o maior peso de sua produção científica concentra-se em trabalhos apresentados em Congressos ou Reuniōes, divulgados em Anais ${ }^{3}$.

Ainda que, recentemerte, venha ocorrendo uma política de incentivo ao desenvolvimento da pesquisa na enfermagem, através de recomendações às instituições de ensino no sentido de despertar nos estudantes o hábito pela pesquisa e aos chefes dos Serviços de enfermagem para que utilizem a pesquisa em seu trabalho com o objetivo de se obter elementos para sua avaliação, é importante considerar que existem alguns fatores limitantes ao desenvolvimento dessa atividade.

Em seu estudo, LOPES ${ }^{6}$ identifica alguns fatores que estão limitando o desenvolvimento da pesquisa no campo da enfermagem. Dentre eles ciestacam-se o desinteresse da instituição empregadora em que o enfermeiro faça pesquisa limitando a possibilidade de crescimento profissional, bem como a alta rotatividade dos enfermeiros nos serviços e a inconstância das suas atividades devido às mudanças de turno de trabalho. Ressalta ainda os impecilhos representados pela sobrecarga de atividades, nem sempre específicas do Serviço de Enfermagem e a falta de conhecimento sobre metodologia de pesquisa. O fator "tempo" esteve sempre presente nas dificuldades apontadas pelos enfermeiros para a realização de pesquisas, quando associado às condições de trabalho. Por sua vez, a falta de espaço físico, a inexistência de bibliotecas para consulta nos serviços de saúde e a não participação desses profissionais nos programas de educação continuada, também foram considerados sérios obstáculos à qualificação dos enfermeiros assistenciais para a pesquisa.

Encerrando suas considerações, o autor ${ }^{6}$ coloca que, devido a essas dificuldades, os enfermeiros assistenciais não têm acompanhado o desenvolvimento da pesquisa no Brasil e se consideram marginalizados desse processo, apesar de se sentirem motivados e interessados no desenvolvimento da pesquisa. 
Diante desse quadro, as Instituições de Ensino $e$ as Entidades de Classe, representadas pela $\mathrm{ABEn}$, enquanto compromissadas com a formação do profissional, já em 1978, por iniciativa do Centro de Estudos e Pesquisas em Enfermagem (CEPEn) propuseram a realização do Seminário de Pesquisa em Enfermagem (SENPE), objetivando a reflexão e a discussão ampla da pesquisa em abordagens diversas, porém inter-relacionadas e progressivas. Esse $1^{\circ}$ Seminário ${ }^{10}$, realizado em Ribeirão Preto (SP), em 1979, teve como meta debater mais amplamente, entre os enfermeiros ,as linhas gerais de pesquisa em enfermagem, a pesquisa cenirada nas necessidades de enfermagem no Brasil e a revisão de estudos já realizados. Nessa ocasião discutiram-se as prioridades e as dificuldades da pesquisa em enfermagem, sua aplicação na prática profissional, bem como os seus progressos.

No entanto, este $1^{\circ}$ Seminário limitou-se a um grupo restrito de profissionais, tendo em vista o seu caráter de iniciação ao tema proposto.

Em 1982, foi realizado um Seminário ${ }^{2}$, em Brasília (DF), onde discutiu-se o delineamento das áreas de pesquisa e suas respectivas linhas. Em 1984, em Florianópolis (SC), teve lugar o Seminário Nacional de Pesquisa em Enfermagem ${ }^{9}$ onde foram abordadas as alternativas de interpretação metodológica na formulação do conhecimento, ressaltando aquelas que se adequam aos problemas da prática de enfermagem no nosso país.

Dentro dessa mesma abordagem foi realizado, em 1985, o Seminário Nacional de Pesquisa em Enfermagem 8, cujo tema central foi "Pesquisa em Enfermagem - Metodologia e Prática", onde os enfermeiros se reuniram visando alcançar uma etapa a mais, iniciando-se a análise da incorporação dos resultados de pesquisa na prática de enfermagem.

Mais recentemente, em 1988, foi realizado em Belo Horizonte (MG), o Seminário Nacional de Pesquisa em Enfermagem ${ }^{7}$ com o tema central "Pesquisa e Serviço de Enfermagem". Nesse seminário, que contou com presença significativa de enfermeiros assistenciais, foram oferecidos cursos nas diversas metodologias de pesquisa e grupos de discussão para refletir sobre a pesquisa nos serviços e no ensino de graduação, onde foram identificados vários aspectos pertinentes às dificuldades na realização de pesquisas, já referidas anteriormente.

Esses seminários foram possibilitando um despertar para a questão da pesquisa em enfermagem sob a perspectiva dos enfermeiros assistenciais. Como fazer com que essas discussões sobre a pesquisa e as diferentes formas de realizá-la chegassem a esses enfermeiros era algo que passou a nos inquietar. De forma mais decisiva, a temática abordada no Seminário Nacional de Pesquisa em Enfermagem ${ }^{9}$ deu-nos subsídios para reflexão e despertou em nós a necessidade de estar levando aqueles conhecimentos para fora dos limites acadêmicos, a fim de que os enfermeiros assistenciais pudessem ter acesso às questões relacionadas à pesquisa, tentando superar assim, uma das barreiras existentes para o desenvolvimento de pesquisa por parte desses profissionais. 
Tendo cm vista que os cursos de Extensão Universitária destinamse a graduandos e graduados com a finalidade de difundir conhecimentos e técnicas de trabalho para aprimorar os padrões culturais dessa clientela *, utilizamo-nos dessa modalidade para viabilizar nossos anseios e aterider a essa necessidade que se evidencia dia-a-dia entre os enfermeiros assistenciais.

Assim sendo, propusemos já em 1984, o curso "Pesquisa e Prática de Enfermagem" para enfermeiros que exercem suas funções em instituições de saúde de nossa comunidade. Para esse curso houve uma demanda além das nossas expectativas o que veio confirmar a carência de investimento nessa área e referendar nosso propósito de continuar oferecendo o curso em anos subseqüentes.

Passamos a seguir a discorrer sobre a dinâmica, os objetivos e os programas desses cursos.

\section{DA PROPOSTA DOS CURSOS E SUA ANALISE}

Com o objetivo de divulgar a produção do conhecimento científico e correlacionar os resultados dessa produção à prática profissional é que propusemos o primeiro curso de Extensão Universitária "Pesquisa e Prática de Enfermagem" em 1984, destinado a enfermeiros assistenciais e oferecido pela Escola de Enfermagem de Ribeirão Preto - USP, com uma carga horária de 45 horas, num total de 15 semanas, sendo 3 horas semanais.

A coordenação deste curso foi feita por um docente da Escola dc Enfermagem de Ribeirão Preto - USP e um enfermeiro assistencial que, então, exercia suas funções junto à Divisão de Enfermagem do Hospital das Clínicas de Ribeirão Preto. $O$ fato da coordenação do curso ser exercida por um docente e um enfermeiro assistencial vem refletir uma postura filosófica que assumimos no sentido de um "compartilhar-com" de forma efetiva.

O conteúdo do curso procurou abranger os seguintes tópicos: história da produção científica em enfermagem; abordagem das alternativas metodológicas; positivismo lógico; materialismo histórico-dialético; fenomenologia e análise de estudos que contribuem para o desenvolvimento da ciência e tecnologia em enfermagem, para humanização da assistência e compreensão da prática de enfermagem.

Foram oferecidas quarenta vagas e a demanda superou nossas expectativas, fazendo com que houvesse uma lista de espera por desistências.

O conteúdo foi desenvolvido através de aulas teóricas formais, ministradas por pessoas que detêm um saber dentro de cada abordagem metodológica proposta. Essas aulas visavam fornecer a fundamentação

- Resolucano ne 1709. D.O. de 16 de outubro de 1979 - Reltor da USP - que dispס̃e sobre cursos de especializaç̆o, aperfelcoamento, extensăo universitária e difusão cultural. 
teórica de cada metodologia, ressaltando os seus pressupostos quanto às diversas concepções de ciência, às possibilidades de produção do conhecimento, bem como sobre as formas de lidar com o objeto da pesquisa, visto sob óticas diferentes.

A seguir, a proposta do curso evidenciava o conteúdo teórico levado a um contexto prático e para tanto, trabalhos realizados, segundo cada uma das metodologias, foram selecionados e apresentados aos enfermeiros pelos seus autores. Cabe ressaltar que, além da questão metodológica, a relevância do trabalho para a prática de enfermagem foi outro critério que norteou a seleção. Essa dinâmica implicava na leitura prévia dos trabalhos a serem analisados, ficando um grupo de participantes responsáveis por dinamizar e direcionar as discussões para os pontos essenciais.

No decorrer do curso foram indicadas referências bibliográficas específicas sobre cada tema abordado. $O$ critério de avaliação adotado pela coordenação vem refletir a preocupação que envolveu todo o planejamento do curso: possibilitar aos enfermeiros o pensar a pesquisa no seu cotidiano de trabalho.

Desta forma, ao final do curso, o enfermeiro deveria apresentar, por escrito, um problema por ele identificado na prática, que merecesse uma análise segundo uma das metodologias de pesquisa apresentadas.

A fim de obtermos subsídios para o aprimoramento de futuros cursos, elaboramos um instrumento de avaliação (anexo 1) constando de duas partes: a primeira, semi-estruturada que direcionava os itens a serem avaliados e a segunda, que possibilitava uma avaliação livre.

A análise dessas avaliações mostrou que a carga horária foi adequada havendo referência de que a mesma poderia ser ampliada para melhor distribuição do conteúdo que foi considerado bom, correspondendo às expectativas do giupo. Houve ainda manifestações positivas quanto aos trabalhos selecionados para apresentação e discussão. A dinâmica, bem como o assessoramento dodo pela coordenação, também foram considerados bons pela maioria. $O$ método de avaliação parece ter atingido o seu propósito, considerando que as avaliações o qualificaram como apropriado, criterioso, válido, interessante e incentivador.

Da mesma forma, as avaliações quanto à validade do curso para o campo de atuação, evidenciaram que o mesmo propiciou oportunidade de um novo "ver a pesquisa", como "algo mais simples", "mais próximo" e "mais acessivel". Expressaram ainda que o curso despertou-os para leitura, impulsionou-os para novas idéias e divulgou a produção de conhecimento de enfermagem para o pessoal de campo. Vale ressaltar que surgiram também opinióes no sentido da importância da continuidade do curso e da dificuldade que representa para o enfermeiro fazer pesquisa sem assessoramento de um orientador.

Analisando essas avaliações e buscando suas convergências, percebe-se que esse curso se mostrou aos olhos dos enfermeiros como um "entrar para a pesquisa". Foi ainda visto como uma oportunidade de reflexão sobre a prática profissional, expressada por eles como "um trabalho 
diário, rotineiro, sem pensar". A preocupação com o cotidiano do trabalho profissional também surgiu nas avaliaçōes onde os enfermeiros vislumbram a possibilidade de integração entre docentes e enfermeiros para crescimento da profissão.

Assim é que, em 1986 oferecemos novanzente o curso dentro da mesma proposta de coordenação compartilhada, envolvendo docentes da escola e um enfermeiro assistencial com atividades junto à Comissão de Educação Continuada do Hospital. A carga horária foi alterada, passando para 58 horas.

O conteúdo ficou acrescido de uma aula teórica ministrada por especialista que abordou a questão dos métodos compreensivos enquanto forma de produção de conhecimento, utilizando o referencial de Weber, scgundo a abordagem de FREUND ${ }^{5}$. Julgamos esse conteúdo prévio importante para a introdução da fenomenoiogia enquanto alternativa metodológica para pesquisa. Também foi destinado mais tempo para a aula que introduzia o positivismo lógico de Conte, conforme análise de CUPANI ${ }^{4}$, salientando sua importância para o desenvolvimento das ciências e do método científico.

A dinâmica adotada, a exemplo do curso anterior, visou dar aos enfermeiros a fundamentação teórica necessária para compreensão e análise dos trabalhos que foram selecionados, mantendo-se os mesmos critérios já referidos para essa seleção. A apresentação pelos autores, seguiam-se discussões dinamizadas pelo grupo que lera previamente os trabalhos.

Com a preocupação de tornar mais viável aos enfermeiros a leitura prévia desses trabalhos, assegurando uma discussão mais rica do conteúdo e da metodologia, a coordenação destinou uma carga horária semanal para essa tarefa, de modo que os encontros formais ocorreram quinzenalmente.

O critério de avaliação foi mantido, bem como a solicitação para que os enfermeiros, ao final do curso, o avaliassem de forma semi-estrututurada e/ou livre. (Anexo 1, já referido). Essas avaliaçōes possibilitaram que a coordenação percebesse que algumas de suas condutas não produziram o resultado esperado; os espaços livres semanais previstos para leituras não se mostraram, aos alunos, como algo positivo; ao contrário, no seu entendimento isto tornou o curso "extenso" e fez com que o interesse não se mantivesse presente. As avaliações refletiram também dificuldade na compreciss̃io da fundamentação teórica (por falta de pré-requisitos, segundo as falas dos enfermeiros) e a idéia de uma "entrada para a pesquisa". Mostraram ainda que havia uma expectativa de maior exigência em relação ao critério de avaliação adotado pela coordenação. Jilgamos essa expectativa extremamente interessante e expressa, a nosso ver, a necessidade, o anseio de cobrança dos enfermeiros, o que de certa forma, lhes garantiria uma "obrigação" de fazer pesquisa.

As experiências destes dois cursos nos animaram a continuar, uma vez que nossa postura é de que é preciso contemplar os enfermeiros assis- 
tenciais com subsídios que os encoragem a produzir conhecimentos. Assim, em 1988 o curso foi proposto pela terceira vez, com algumas reformulaçōes advindas das experiências anteriores: um conteúdo teórico inicial é introduzido com a finalidade de se fazer uma análise histórica da profissão de enfermagem, procurando abordá-la de forma ligada à história da saúde e analisando as diferentes conceituações que tem assumido a longo da história.

Ao lado desse conteúdo, procuramos também introduzir a discussão da evolução das diferentes formas de se "fazer enfermagem" através de conteúdo sobre modalidades de assistência de enfermagem.

A apresentação do conteúdo sobre as alternativas metodológicas foi mantida, acrescida agora de uma aula sobre método científico ressaltan. do suas etapas operacionais. Esse conteúdo foi ministrado após o positivismo lógico e complementado com análisc de estudos, a título de ilustração, que possibilitasse aos enfermeiros o reconhecimento dos pressupostos do positivismo e de cada etapa do método, presentes nesses estudos.

Ainda em relação ao curso ministrado em 1988, a coordenação pretendeu que ao seu término, para fins de avaliação, os enfermeiros apresentassem um plano de pesquisa, ainda que de forma incipiente. Este plano deveria envolver temática relacionada ao seu cotidiano de trabalho e a forma metodológica proposta para a realização da pesquisa.

Para a elaboração desse plano oferecemos um roteiro opcional que listava alguns itens a serem considerados quando da realização do plano. No item relativo à introdução, o enfermeiro deveria caracterizar o local de trabalho, as situações vivenciadas no seu cotidiano, relacionadas ao tema escolhido, a seleção de uma situação ou problema a ser estudado, a delimitação do problema e os objetivos.

No item relativo ao procedimento, o enfermeiro deveria explicitar a metodologia selecionada para atingir os objetivos e o planejamento da forma como pretendia trabalhar os dados.

As avaliações sobre o curso, realizadas ao seu final pelos enfermeiros, retrataram de forma clara algumas intercorrências especificas deste ano, relacionadas a um movimento de paralização na Úniversidade $e$ que prejudicaram o aproveitamento como um todo. A interrupção prolongada que o curso sofreu em conseqüência dessa paralização ocasionou uma ruptura e uma evasão que não nos foi possivel recuperar. Com isso, cerca de $50 \%$ dos enfermeiros chegaram até o final do curso, em decorrência das alterações no cronograma, das dificuldades de comunicação dessas alteraçōes e da perda da motivação por parte de docentes e discentes.

Ainda assim, ao final foi possivel um momento de reflexão que nos possibilitou visualizar novos horizontes para futuros cursos. 


\section{REVENDO A EXPERIENCIA}

Pareceu-nos importantc avaliar, num segundo momento, o significado que esses cursos possam ter tido para os enfermeiros que por eles passaram. Trazer à luz facetas desse significado, a nosso ver, representa um caminho para repensar essa experiência e encontrar formas que possam dar-lhe novas dimensões.

Para tanto, decorrido um tempo, pensamos em resgatar com esses enfermeiros, alguns dados relacionados à proposta dos cursos. Elaboramos então um instrumento para levantar dados que possibilitasse a obtenção de informações relativas a atividades que vêm sendo desenvolvidas pelos ex-alunos e que, de alguma forma, estejam relacionadas ao tema proposto. Pensamos ainda nesse instrumerto como forma de retomar a questão da motivação dos enfermeiros quando da sua procura pelo curso e de como vêem hoje a contribuição que o mesmo lhes possa ter dado.

Esse instrumento foi testado em um grupo de enfermeiros e, após algumas modificações que se fizeram necessárias, foi encaminhado para preenchimento a 85 enfermeiros dos 103 egressos desses cursos; essa diferença numérica decorreu de dificuldades de localização dos mesmos, por mudanças de emprego ou abandono de profissão.

Dos 85 instrumentos enviados, obtivemos um retorno de $37(43,5 \%)$ e fundamentados no material desse levantamento é que faremos a análise possivel.

Assim, os enfermeiros que procuraram pelos cursos, exerciam suas funções predominantemente num hospital geral escola, havendo alguns poucos que atuavam em Centros de Saúde e Hospitais Conveniados. O tempo de serviço desses enfermeiros variou de 2 a 24 anos, observandose uma maior concentração na faixa de 4 a 7 anos. Observou-se também que a procura se deu predominantemente por enfermeiros, sem cargos diretivos, ou seja, aqueles que estão vivenciando a prática de forma mais presente. Estas evidências nos remetem às considerações feitas inicialmente, sobre um período que tem se mostrado critico aos enfermeiros, decorrido algum tempo do início de sua prática, quando ocorre um esvaziamento em termos de realização pessoal que leva à busca de novas perspectivas.

No que se refere à motivação para o curso, as falas dos enfermeiros revelaram predominantemente uma preocupação em melhorar conhecimentos de pesquisa e assim melhor fundamentar a sua prática, havendo ainda algumas referências no sentido de planos para carreira universitária e uma possivel pós-graduação.

O levantamento possibilitou ainda verificar que 27 enfermeiros referiram ter desenvolvido pelo menos uma pesquisa, sob diversas formas de participação, destacando-se a realização como autor principal, seguida de co-autoria. Estes dados podem refletir uma nova postura do enfermeiro de serviço frente à pesquisa e isto vem reforçar nossa convicção da necessidade de investimento neste campo. 
Essa convicção advém da percepção de um evoluir em termos de atividades de pesquisa dos enfermeiros, considerando que sua participação, na maior parte das vezes, se dava apenas como colaborador no processo de coleta de dados em pesquisa de outros profissionais, sem que ao menos tivessem conhecimento da pesquisa como um todo. Essa participação se dava assim de uma forma alienada do contexto da pesquisa, onde o enfermeiro não conhecia os objetivos e os resultados da mesma; além do fato de que o seu nome não constava, na fase de divulgação, enquanto colaborador.

A questão da divulgação da pesquisa mereceu um lugar no nosso levantamento e nesse sentido, os dados mostraram que 24 trabalhos realizados foram divulgados, através de congressos, seminários, encontros, divulgação interna e anáis. Gostaríamos de ressaltar aqui, que as vias de divulgação interna que têm sido utilizadas pelo Hospital Escola, de onde tem procedido grande parte da clientela desses cursos, têm se mostrado incentivadoras e criadoras de possibilidades para divulgação do conhecimento produzido pelos enfermeiros.

Entre as causas da não realização de pesquisa apontadas pelos 10 enfermeiros que referiram não ter realizado nenhuma pesquisa, emergiram as questões relacionadas ao exercício profissional propriamente dito. Este fato confirma o que a literatura vem apontando nesse sentido sobre as atividades dos enfermeiros, como algo rotineiro, que tende à acomodação e que, de certa forma, os mergulha num cotidiano de trabalho onde há pouco espaço para a pesquisa.

As pesquisas desenvolvidas se deram na área de atuação dos enfermeiros e se mostraram úteis para sua prática. Isso vem reforçar o que já comentamos em relação aos motivos que levam os enfermeiros à procura por cursos de pesquisa.

Em relação ao propósito do curso de estimular o enfermeiro a pensar a pesquisa no seu cotidiano de trabalho, o instrumento possibilitounos observar que 25 dos 37 enfermeiros responderam que estão dando continuidade à busca de conhecimentos que subsidiem a realização de pesquisas, destacando-se o investimento em leitura e a procura por disciplinas de pós-graduação.

Finalmente, cabe-nos fazer algumas consideraçōes em relação a como esses enfermeiros vêem hoje a aplicabilidade do curso. As suas falas mostraram algumas convergências no sentido de que o curso mostrou-se válido enquanto proporcionou um embasamento teórico, tornou a pesquisa mais acessivel no que se refere a sua concretude e, de certa forma, a sua simplicidade. A pesquisa deixa de ser vista como algo dificilmente atingivel e passa a ser encarada como algo possivel, ressaltando a atuação profissional como fonte primordial de pesquisa.

O fato do conteúdo ter possibilitado diversas alternativas metodológicas também foi um fator importante para contemplar as várias formas possíveis de produção de conhecimento, de acordo com a natureza dos dados e a própria visão de mundo dos enfermeiros. Por outro lado, a 
expectativa dos enfermeiros de que o curso pudesse se converter numa "entrada para a pesquisa" não se concretizou, pois suas falas mostraram que sentem agora que há um longo caminho a percorrer no sentido de ampliar seus conhecimentos de forma a possibilitar a capacitação básica para realizar pesquisa.

Enquanto caminho para mostrar outros horizontes e para reflexão sobre o exercício profissional, os cursos mostraram-se válidos aos olhos dos enfermeiros.

\section{CONSIDERAÇOEES FINAIS}

Da análise da experiência desses três cursos, vemos hoje, de forma mais clara e abrangente, a questão da produção do conhecimento por parte dos enfermeiros assistenciais. Parece-nos imprescindivel que esses enfermeiros recebam a fundamentação teórica necessária para que possam vir a agilizar essa produção e pensamos ser esta uma responsabilidade das escolas de enfermagem. como tal precisa ser utilizada: é uma via também para a integração docente-assistencial.

Por outro lado é necessário também que a responsabilidade seja compartilhada, ou seja, que os enfermeiros, ao procurarem esses cursos, se desvistam de um papel passivo, de mero receptor de informaçōes para se posicionarem enquanto sujeitos de sua formação para a pesquisa.

Vemos também que o curso que vimos oferecendo, ainda que tenha tido o mérito de "iniciação" dos enfermeiros para a pesquisa, precisa sofrer novas reformulações que o revista de um caráter mais formativo que informativo. Observamos nos enfermeiros, mais que uma necessidade, uma ansiedade em saber fazer pesquisa e quando procuram o curso com nome tão sugestivo - "Pesquisa e Prática de Enfermagem" trazem consigo essa expectativa de aprender a fazer pesquisa. Temos sentido a responsabilidade com que a coordenação do curso se reveste diante dessa expectativa e percebido um constante caminhar de 1984 a 1988, caminhar esse que só foi possivel através da convivência com enfermeiros de serviço e da possibilidade de entendê-los nas suas dificuldades de várias ordens.

Isto nos leva a planejar o curso em novas bases para 1990:

- a carga horária precisa ser substancialmente aumentada (um mínimo de 30 horas) o que acarretará uma mudança na sua forma: passa de extensão universitária à aperfeiçoamento, de acordo com regulamentação própria da USP;

- é preciso investir mais na questão do método positivista ressaltando as caracteristicas de uma INTRODUÇĀO, com o levantamento bibliográfico, delimitação do problema, formulação de objetivos, hipóteses e procedimento - a questão de padronização de técnicas, de observador, de instrumental, de elaboração de instrumentos, teste 
de instrumentos, validação, questōes relativas a amostragem, de forma que os enfermeiros possam ir compreendendo e refeltindo sobre cada um destes itens. Estratégias deverão ser selecionadas para consolidar esses conhecimentos, tais como leituras, discussões, treinos;

- após estes conhecimentos terem uma certa sedimentação é que os enfermeiros poderão melhor apreender outras formas metodológicas de se fazer pesquisa, as chamadas alternativas de pesquisa como é o caso da fenomenologia e do materialismo histórico - dialético. $\mathbf{O}$ processo aí, a exemplo do positivismo lógico, precisará ser detalhado com toda terminologia própria de cada uma delas e com o seu método ou trajetória. Além da fenomenologia vemos que outras modalidades da pesquisa qualitativa precisam ser contempladas num curso como este;

- a questão da dinâmica adotada pela coordenação tem se mostrado satisfatória e, vemos portanto que trabalhos contemplando as várias metodologias continuariam a ser apresentados por seus autores segundo os critérios já expostos;

- acreditamos que o critério de avaliação adotado em 1988 deva permanecer, mas o plano de pesquisa seria elaborado durante o curso e não ao seu final. A nosso ver isso implica num assessoramento mais presente e constante por parte dos coordenadores do curso que necessitarão assumir esse encargo;

- vemos também a possibilidade de encaminharmos os enfermeiros ao término do curso para alguns orientadores, professores da Escola de Enfermagem de Ribeirão Preto - USP, que se disponham a trabalhar, junto com os enfermeiros, de acordo com a especificidade do seu conhecimento e de sua metodologia, numa atividade de pesquisa compartilhada. Sob esse enfoque julgamos ter conseguido algum avanço considerando que a autoria deste trabalho foi compartilhada com uma enfermeira assistencial, ex-aluna do curso que vimos desenvolvendo.

BOEMER, M.R.; SANTOS, B.M. de O.; AGUILLAR, O.M.; STOPA, M.J.R. An alternative proposal for scientific production by nurse practitioners. Rev. Esc. Enf. USP, São Paulo, 24(2):211-223, Aug. 1990.

We report our experience with University extension courses on research methodology offered to nurse practitioners in order to provide them with some fundaments about the topic. These courses, which were given in 1984, 1986 and 1988 by the Nursing School of Ribeiräo Preto-USP, were proposed by the coordinators who felt it is necessary to stimulate the scientific production of nurse practitioners; thus, the basic proposal of the courses was to promote this stimulation, thus, in addition to presenting the content of different research methodologies, the courses discussed nursing research that appeared to be relevant for practice. Some time after the courses were given, the nurses who had taken them were approached in ordem to obtain information to be used for the elaboration of future courses and to evaluate the contribution made by the initial courses in terms of stimulaiton of research by nurse practitioners.

UNITERMS: Nursing research. Nursing practice. Teaching nursing. 


\section{REFERENCIAS BIBLIOGRAFICAS}

1. ALMDIDA, M.C.P. et alli. A produç̆o do conheclmento na pós-graduaç̆o em enfermagem no Brasil. In: CONGRESSO BRASILEIRO DE ENFERMAGEM, 33., Manaus, 1981. Anais, Manaus, Associaç̆o Brasileira de Enfermagem, 1981. p. 119-28.

2. AVALIACAO e perspectivas: ciencias da sadide - enfermagem. Brasilia, Secretaria de Planefamento, 1982. v.6. p. 146-59.

3. CONSHLHO FWDHRAL DE ENFERMAGEM. O exercicio da enfermaxem nas institulec̃es do vatido do Bravil 1982/1983: lorç do trabalho om enfermagem. Rlo de Janelro, Associactio Brasileira de Enfermagem, 1985. V.1.

4. CUPANI, A.O. Positivismo, neopositivismo $\theta$ funcionalismo. In: SEMINARIO NACIONAL DE PESQUISA EM IFNFERMAGEM, 3., Florlanópolis, 1984. Anais, FlorianóDolis, 1984. D. 87-103.

. 5. FREUNO, J. Sociologia de Max Wober. Rio de Janeiro, Forense Universitária, 1975.

6. LOPES, C.M. A produç̃o dos enfermetros assistenciais em relacão à pesquisa em enfermagem, em um municiplo paulista. Ribeiræo Preto, 1983. 133 p. (Dissertacăo de mestrado - Escola de Enfermagem de Ribelrão Preto da USP).

7. SEMMTNARIO NACIONAL DH PESQUISA FM FNFERMAGHM, 5., Belo Horizonte, 1988. Anais, Belo Horizonte, Associacåo Brasileira de Enfermagem, 1988. 131p.

8. SEMMINARIO NACIONAL DE PESQUISA EM ENFERMAGEM, 4., São Paulo, 1985. Anais. Săo Paulo, Assoclacão Brasilleira de Enfermagem, 1985. $280 \mathrm{p}$.

9. SEMINARIO NACIONAL DE PESQUISA EM ENFGRMAGEM, 3., Florian6polis, 1984. Anais. Florianópolis, Universidade Federal de Santa Catarina, 1984. 376 p.

10. SEMINARIO NACIONAL DE PESQUISA EM ENFERMAGEM, Ribeirøo Preto, 1979.

Relatório. Rlbeirăo Preto, Assoclaç̊̆o Braslleira de Enfermagem, 1979. 148p.

\section{ANEXO I \\ CURSO DE EXTENSÃO UNIVERSITARIA: PESQUISA E PRATICA DE ENFERMAGEM}

\section{Avaliacão}

Ao término desse curso, seus coordenadores sentem a necessidade e o dever de ouvir dos alunos sua validade e, nesse enfoque, vêem solicitar que expressem sua opinião a respeito do referido curso.

Sugerimos alguns itens para respostas que nos fornecerão subsídios para cursos futuros sendo, portanto, de extrema importancia a sinceridade das respostas. Entretanto, a sugestãa de ítens para respostas não exclui a possibilidade do aluno optar por uma avaliação livre, que não se prenda a nenhum dos ítens propostos.

Não é necessário que vocé assine sua avaliação; façamo apenas se quiser.

Agradecemos sua colaboração e participação nesse curso.

\section{A Coordenaçăo}

\section{ITENS PROPOSTOS PARA AVALIACGAO}

- Quanto a carga horária:

- Quanto ao conteúdo através de aulas expositivas:

- Quanto à seleção dos trabalhos apresentados:

- Quanto à dinamica de trabalho adotada para os grupos:

- Quanto ao conteúdo corno um todo:

- Quanto ao assessoramento da Coordenação:

- Quanto ao método de avaliação utilizado:

- Quanto a sua validade para o seu campo de atuação:

AVALIAÇA LTVRE: 


\section{ANEXO II \\ Levantamento de dados sobre o Curso de Extensăo Universitária \\ "PESQUISA E PRATICA DE EINFERMAGEM" - 1989}

Nome:

Endereço:

Local de Trabalho: Hospital-

Clínica-

Tempo de Serviço como Enfermeira:

Cargo ou Função: no momento do cursa-

atualmente-

Ano em que fez o curso:

1 - O que motivou a procura do curso?

2 - Realizou ou está realizando alguma pesquisa?

Sim ( ) Nåo ( )

- autor - individual ( )

- principal ( )

- co-autor ( ) - colaborador ( ) especificar:

- ano de participação na pesquisa

3 - Caso sua resposta tenha sido positiva, houve divulgaçao dos resultados?

- $\operatorname{Sim}($ ) Não $($ )

- divulgação interna ( )

- divulgação em: - seminários, encontras etc. ( )

- congressos ( )

- periodicos $($ )

- anais ( )

- outros ( ) especificar

4 - Caso sua resposta tenha sido negativa, identifique as prováveis causas.

5 - O trabalho foi desenvolvido na sua área de atuação?

Sim ( ) Não ( )

6 - Os resultados tem sido úteis para a sua prática? $\operatorname{Sim}($ ) Não ( )

7 - Após a realização do referido curso, buscou outras fontes para aumentar seus conhecimentos em Pesquisa?

Sim ( ) Não ( ) Especificar:

Especificar:

8 - Você entregou seu trabalho para a avaliaçåo final do curso? Sim ( ) Não ( )

$\rightarrow$ Em caso negativo, de as razб́es que a levaram a nåo entregar:

9 - Hoje, decorrido algum tempo de realização do curso, como voce vê a sua aplicabilidade na prática?

Recebldo em 29-06-89. 